\title{
Representatividade negociada: feminilidade, raça e gênero na publicidade
}

Marcelle Barreto Felix da SILVA ${ }^{1}$

\section{Resumo:}

Este artigo debate a questão dos sentidos da feminilidade, tentando entender como são construídos nos anúncios publicitários. Pouco se sabe, em termos quantitativos, como mulheres negras são representadas em anúncios. A pesquisa analisou 6.913 peças publicitárias da revista Veja entre os anos de 2002 a 2017. Os resultados apontam que mulheres negras são o grupo mais sub-representado na publicidade, além de estarem mais frequentemente associadas a estereótipos e produtos mistos ou não lidos como tipicamente femininos. As mercadorias compreendidas como femininas se direcionam de forma majoritária às mulheres brancas.

Palavras-chave: Publicidade brasileira. Feminilidade. Raça. Gênero.

\section{Negociated representativeness: femininity, race and gender in advertisement}

Abstract:

This article discusses how the senses of femininity are constructed in advertisement. Only a few researches with quantitative data analyses show how black women are represented in advertisement in Brazil. The author examined 6.913 advertisements in Veja magazine during the years of 2002 to 2017. Quantitative data analyses reveal that black women are the most underrepresented group, are frequently portrayed in a stereotypical way and are associated with gender mixed products or itens that are not seen as typically feminine. The products normally associated with femininity are represented by white women.

Keywords: Brazilian Advertisements. Race. Gender.

\section{Representatividad negociada: femininidad, raza y genero en la publicidad}

\section{Resumen:}

Este trabajo discute como los sentidos de la femininidad son elaborados en la publicidad. Hay poca información académica sobre como mujeres negras son representadas en los comerciales. La autora analisa 6.913 anúncios en la revista Veja en los anos de 2002 hacia 2017. El estudio que se presenta concluye que el grupo es lo más sub representado. Además, se concluye que las mujeres negras son asociadas a estereotipos y productos mistos en términos de género o mercaderías no lidas como típicamente femeninos. Las mercancías comprendidas como femeninas son representadas mayoritariamente por mujeres blancas.

Palabras clave: Comerciales de Brasil. Femininidad. Raza. Genero.

\footnotetext{
${ }^{1}$ Mestre em Sociologia pelo Instituto de Estudos Sociais e Políticos da Universidade do Estado do Rio de Janeiro (IESP/UERJ). Doutoranda em Sociologia pelo IESP/UERJ.
} 
Introdução

Embora os efeitos da publicidade sobre o seu público sejam largamente estudados e, ainda, bastante controversos, é difícil negar a exposição frequente das pessoas a esse meio de comunicação. A ampliação da divulgação de peças publicitárias para os mais diversos espaços - das plataformas digitais até os tradicionais anúncios de jornal - torna a questão da representação em anúncios relevante socialmente, já que mobiliza códigos culturais e acaba por reafirmar ou contestar determinados papéis e hierarquias sociais já existentes. $\mathrm{O}$ anunciante se vale de discursos anteriormente utilizados, aceitos e legitimados pela tradição cultural, já que é a mobilização de códigos estabilizados que dá sentido ao discurso publicitário. No entanto, as transformações sociais em alguma medida ressignificam alguns valores já socializados, o que faz com que, a depender do públicoalvo, a peça precise negociar com as expectativas sociais que emergem (CARRERA; OLIVEIRA, 2013).

Cabe ressaltar que, embora haja uma demanda por representatividade e diversidade na publicidade, o papel desta não é de gerar um retrato fiel da realidade. Seu objetivo é ampliar as vendas ou valorizar determinada marca, o que pode ou não esbarrar no tópico da representatividade ou diversidade. Algo fundamental no processo de persuasão de anúncios é a formação de um canal de identificação da peça com a audiência. Os consumidores procuram marcas que sejam compatíveis com a sua autoimagem real como o indivíduo vê a si mesmo -, a autoimagem ideal - como ele gostaria de se enxergar - e a autoimagem segundo as pessoas ao seu redor, isto é, como um indivíduo acha que é visto pelos demais (KOTLER; KELLER, 2012). Assim, a cultura é fator fundamental para compreender o universo do público-alvo, considerando também características demográficas como gênero, raça e classe social.

Para elaborar a publicidade, busca-se saber informações sobre o perfil social do público-alvo. Nesse sentido, o gênero dessa audiência é relevante para a formulação da peça, sendo um perfil que, quando bem direcionado, é de fácil identificação e alta lucratividade. Em outras palavras, o público feminino e masculino é de fácil mensuração e resposta relativamente rápida, o que torna a divisão de segmentos por gênero lucrativa na publicidade (WOLIN, 2003). Embora o apelo racional seja explorado, a publicidade tem como prioridade o apelo emocional ao leitor para que a persuasão seja eficaz, buscando a sua identificação em um corpo "investido de valores socialmente especificados” (MAINGUENAU, 2001 apud CARRERA 2016, p. 39). 
A análise das narrativas dos anúncios não identifica somente o que se vê, mas o que os resultados podem contribuir para entender alguns sintomas sociais. Segundo Kotler e Keller (2012), um anúncio bem-sucedido visa a estabelecer uma relação entre a marca e o consumidor, o que leva em consideração pesquisa de público, fatores sociais, culturais e psicológicos, tentando gerar, sobretudo, a identificação da audiência com a mensagem transmitida pela marca. Nesse contexto, este artigo visa a contribuir para a discussão de como as peças que representam mulheres fazem a construção de uma ideia de feminilidade e como a mulher negra se encaixa nessa narrativa.

\section{Feminilidade e representação}

Uma pessoa pode nascer e ser socialmente vista como uma mulher, mas não ser socialmente reconhecida como tal. Para Bartky (1990), a cultura patriarcal constrói uma ideia de feminilidade, que é difundida por meios de comunicação, por instituições e também cotidianamente pelos indivíduos. Ela pode ser percebida socialmente a partir de gestos, práticas e aparências acordadas socialmente como femininas. Seu trabalho toma como base o pensamento de Foucault a respeito das práticas disciplinares da modernidade, que são canalizadas por meios não necessariamente violentos, mas que produzem tecnologias de autocontrole e constante vigilância entre os indivíduos. A forma de dominação masculina moderna se expressa sob o controle da feminilidade dos corpos das mulheres. Esse corpo se molda a determinadas regras que exprimem uma relação de poder e um status inferior. Segundo a filósofa, a feminilidade apresenta três direcionamentos fundamentais: normas sobre tamanho e aparência do corpo - como ser magra e alta, por exemplo -; regras a respeito da postura e gestos femininos; normas sobre como produzir e ornamentar esse corpo - com maquiagens, cuidados com a pele e cabelos, entre outras.

A feminilidade ideal, no entanto, traça metas em grande medida inalcançáveis, de modo que quem decidir perseguir esse alvo irá se frustrar, ao menos parcialmente. São muitos os critérios e efeitos dessa feminilidade, há uma postura de certa deferência, amabilidade, de se reservar no espaço que são reconhecidos culturalmente como próprios da mulher. O trabalho de Young, 1980 (apud BARTKY, 1990) mostra como as mulheres tendem a ficar menos à vontade quando estão em público, e isso se manifesta nos seus movimentos, em geral mais contidos do que o dos homens. Isso se dá porque na sociedade patriarcal, os desejos da mulher não devem ser concretizados livremente, o que se expressa em seu corpo e seus movimentos mais contidos. Ainda segundo Bartky (1990), 
a feminilidade conta com três imperativos: limitação, graça e erotismo, o que parece se dar num constante equilíbrio, pois uma dose exagerada de cada já pode gerar um desvio. Para além da opressão, o exercício da feminilidade traz algumas vantagens para as mulheres, como maior acesso a oportunidades na vida profissional e a relações afetivas (BARTKY, 1990).

O alcance das peças publicitárias e de filmes que exibem modelos de mulher ideal virtual nunca foi tão extenso e nunca atingiu um número tão expressivo de mulheres, independentemente da classe social. Embora a busca particular pela beleza não seja uma novidade, a produção e ampliação de aparatos tecnológicos capazes de difundir imagens que propagam uma feminilidade normativa está substituindo outras formas de controle anteriores, representadas por instituições religiosas e escolas (BARTKY, 1990).

$\mathrm{Na}$ análise de Bartky (1990), no entanto, a aparência não conta com o critério racial como passível de gerar diferença relevante ou mesmo central no controle sobre as mulheres. Embora as normas incidam sobre todas as mulheres, a raça restringe e altera as formas de performar essa feminilidade. Se a feminilidade hegemônica exibe imagens de mulheres loiras e magras, as possibilidades de se encaixar no padrão se tornam inviáveis para mulheres não-brancas. Para Tate (2009), mulheres negras trabalham simultaneamente a partir do ideal de beleza e necessariamente contra ele, em um processo de constante negociação, considerando que a concepção do que é belo é historicamente branca.

Xavier (2013) discorre sobre os sentidos de ser mulher negra presentes em anúncios da imprensa negra no período pós-abolição nos Estados Unidos e no Brasil. A historiadora descreve que ser mulher negra em uma sociedade racializada é tentar construir uma "feminilidade mediada pela experiência da escravidão e por seu legado" (XAVIER, 2013, p. 430). Para tal, tentava-se recuperar uma moralidade, a capacidade criativa, o bom comportamento e exaltar a beleza negra - elementos entendidos como fundamentais para recuperar a ideia de cidadania para essas mulheres. Essa realidade trazia como saída para as hierarquias cotidianas o cuidado com a aparência, que traria maiores chances de essas mulheres serem reconhecidas como pessoas em vez de mercadorias, podendo ter acesso a trabalho e a uma possível ascensão social. É o que é identificado pela autora como "beleza cívica" (XAVIER, 2013, p. 430).

Enquanto a pressão para atender a padrões de feminilidade tem sido criticada historicamente pelo feminismo (BEAUVOIR, 1970), para as mulheres negras, a feminilidade tem sido um alvo e uma forma de receber credibilidade como mulher e 
cidadã (XAVIER, 2013). As ideias hegemônicas sobre feminilidade se mostraram incongruentes com a situação na qual as mulheres negras eram colocadas, o que exigiu como resposta a tentativa de construir uma "feminilidade reconstruída" em uma sociedade racializada. Segundo Xavier (2013), notou-se uma preocupação nas mulheres negras de se desvencilhar da imagem bestializada e de mercadoria.

A feminilidade, em um sistema de performance de gênero, é fator que gera identificação entre as mulheres, dialogando com o que se entende por bonito, admirável e amável, características associadas ao grupo. Nesse cenário, a construção da feminilidade na publicidade, com seu grande alcance, é fator importante para se pensar em como as imbricações de raça e gênero se imprimem nos meios de comunicação.

\section{Raça, gênero e publicidade}

Há pesquisas sobre modos de representação de gênero e de raça na publicidade no Brasil e em outros países, sobretudo nos Estados Unidos. Os trabalhos brasileiros são, em geral, qualitativos e focam mais no gênero do que na raça, bem como tratam pouco da perspectiva interseccional de análise. Já nos Estados Unidos há uma abordagem mais extensa sobre raça do que no Brasil. Contudo, os estudos sobre gênero ainda são numerosos e, de modo geral, tendem a ser quantitativos. Em ambos os países, a abordagem interseccional é relativamente escassa e a literatura aponta para a subrepresentação de pretos e pardos e uma representação de gênero um pouco mais igualitária, ainda que conserve papéis de gênero e estereótipos.

Em resposta ao contexto da primeira onda feminista da década de 1960, foram elaborados estudos críticos sobre a representação das mulheres na publicidade. As pesquisas na área são abundantes no âmbito internacional, com mais de cinco décadas de trabalhos a respeito. Com mais pesquisas nos Estados Unidos, que privilegiam métodos quantitativos, é demonstrado que as mulheres são constantemente associadas a ocupações profissionais inferiores, quando não se restringem à área doméstica. Além disso, as modelos costumam ser mais sexualizadas do que os homens nos anúncios (LINDNER, 2004; WOLIN, 2003).

Uma das principais referências na temática de representação de gênero na publicidade é o livro de Goffman (1979), Gender advertisements. Sua metodologia reuniu imagens de revistas selecionadas sem um critério pré-estabelecido, analisando características recorrentes das peças. Como resultado, Goffman (1979) mostrou que mulheres costumam estar em posição espacial ou corporalmente mais baixa do que o 
homem - inclinadas, no chão, sentadas -; elas costumam ser de menor estatura do que homens; costumam tocar em objetos e pessoas, exibindo as mãos como expressão de suavidade; apresentam funções reconhecidas socialmente como inferiores em relação às profissões lidas como predominantemente masculinas (por exemplo, médico e enfermeira). Seu estudo mostra que a mulher se mostra incapaz de resolver situações sozinha, precisando constantemente do apoio psicológico e da decisão do homem.

Desse modo, o trabalho discorre sobre como a hierarquia de gênero é reafirmada na publicidade. Apesar de ser uma referência, a pesquisa de Goffman (1979) foi criticada por não apresentar uma sistematicidade na forma de selecionar as imagens analisadas, perdendo em alguma medida a capacidade de expressar as imagens publicitárias em geral.

A metodologia de Goffman (1979) foi parcialmente reproduzida por outros autores (DÖRING; PÖSCHL, 2006; EISEND, 2010), que optaram por utilizar o método quantitativo. Segundo os trabalhos citados, as mulheres são comumente representadas como donas de casa, desfrutando momentos de lazer, com partes do corpo à mostra ou com papel decorativo. De acordo com o levantamento bibliográfico realizado por Eisend (2010), os papéis mais recorrentes nos quais as mulheres são colocadas nas peças publicitárias são referentes à profissão, como aqueles que requerem cuidado, assistência, amabilidade, recebendo salários mais baixos, enquanto os chamados cargos masculinos são aqueles que apresentam maior status social e exigem uma personalidade mais racional e corajosa. Além disso, as mulheres são mais frequentemente associadas a estereótipos do que modelos homens, com uma taxa de 1,5 a 4 vezes mais alta. No entanto, as pesquisas mais recentes mostram algumas transformações relevantes no modo como as mulheres são representadas: há maior variedade de imagens, além de estarem com maior autoridade (EISEND, 2010; ZOTOS; TSICHLA, 2014).

$\mathrm{Na}$ literatura nacional sobre o tema, encontrou-se em comum o fato de mulheres brancas, magras, com idade entre a juventude e a vida adulta serem a maioria entre as modelos dos anúncios (BELELI, 2005; SHINODA, 2017). Corroborando com Beleli (2005), Shinoda (2017) mostra que a mulher é colocada marcadamente como objeto sexual. Em contrapartida, a autora apontou para uma transformação nessa representação ao longo dos anos, além do maior uso de recursos de quebra de estereótipo, como a mulher com prestígio e autoridade. Os trabalhos de gênero citam a raça de forma marginal, e descrevem, grosso modo, mulheres brancas.

Os resultados das pesquisas estadunidenses mostram que, apesar do aumento crescente de negros nas peças, a sub-representação ainda se faz presente, com poucos 
avanços na qualidade dessa representatividade (GRADY, 2007). Os modelos aparecem em situações ainda estereotipadas, com associações à subalternidade - trabalhos mal pagos - ou a características socialmente reconhecidas como próprias do público negro, como dança e música (COLFAX; STERNBERG, 1972).

A literatura brasileira sobre raça na publicidade já segue o caminho oposto, com maioria de pesquisas qualitativas, com raros trabalhos que levem em conta as imbricações de gênero e raça na qualidade das representações no meio publicitário (FRY, 2007; GASTALDO, 2002; STROZENBERG, 2005). A metodologia e o corpus reduzido fazem com que não se possa aferir a medida da desigualdade na representação racial nesse meio de comunicação.

A desigualdade racial na publicidade apontada nas pesquisas quantitativas brasileiras se mostra tão profunda que parece que os anúncios estão sendo transmitidos para sociedades com perfil estético europeu (HASENBALG, 1982; SILVA; ROCHA; SANTOS, 2012). Segundo Silva, Rocha e Santos (2012), ser branco é a norma de humanidade, entendido como figura ideal para ser representada e gerar identificação nos mais diferentes contextos nos meios de comunicação.

No entanto, o número de negros ao longo dos anos aumentou de forma modesta nas publicidades do Brasil, segundo algumas pesquisas quantitativas. O trabalho de Martins (2009), que observou as peças publicitárias da revista Veja entre 1985 e 2005, apontou um incremento nesse período, passando de 3\% em 1985 para 13\% em 2005. Entretanto, os modelos negros das peças eram insistentemente associados a estereótipos, como artista, atleta e celebridades e o grupo de mulheres negras continuou sendo o mais sub-representado.

Embora sejam descritas algumas particularidades na representação de mulheres negras, essa temática é tratada ainda de modo secundário nos trabalhos citados. A desigualdade de representação em relação a mulheres e homens negros é apontada em termos quantitativos: enquanto o primeiro grupo apresenta 57 modelos no período analisado, o segundo soma 87 (MARTINS, 2009). O autor também aponta para a hipersexualização do grupo feminino. No entanto, as conclusões ainda se voltam majoritariamente para a forma com que homens negros são representados, sem se deter nas peculiaridades do modo como mulheres pretas e pardas aparecem nos anúncios.

Ainda nessa tônica, a maioria dos trabalhos estadunidenses trata de forma marginal ou nula as interseções de raça com gênero, o que traz a necessidade de mais pesquisas que respondam a essa questão. As pesquisas de Baker (2005), realizadas nos 
Estados Unidos, e Sengupta (2006), no Canadá, direcionam-se no sentido de contribuir para essa lacuna, comparando a representação de modelos não brancas às brancas.

A pesquisa de Hazell e Clarke (2008) demonstra que existe um padrão de beleza branco, no qual as mulheres negras apresentam características que se aproximam do ideal branco, com nariz fino, cabelos longos lisos ou cacheados. Além disso, há a objetificação da mulher negra em contraposição a modelos brancos representados como consumidores de produtos - os modelos branco e negro não costumam interagir entre si de modo informal.

As pesquisas que partem de uma perspectiva interseccional são relativamente mais escassas, além de, por vezes, focarem somente no grupo de mulheres negras (HAZELL; CLARKE, 2008). Como afirma Goffman (1979), as imagens das publicidades tendem a ser hiper-ritualizadas, além de serem relacionais, ou seja, a representação de um grupo depende da construção da imagem do outro. Assim, entender a representação de mulheres negras e brancas ajuda a compreender mais a fundo a lógica de representação e de reafirmação ou mesmo contestação de possíveis hierarquias sociais.

No Brasil, as pesquisas que interseccionam raça e gênero na publicidade também são raras (BELELI, 2005; NAVARRO, 2014). Beleli (2005) investiga como sexualidade e gênero são em anúncios impressos, e parte do trabalho considera como a raça funciona como marcador da diferença. A tese conta com o exame de anúncios impressos em anuários de 1975 a 2003 e entrevistas a publicitários. Destaca-se que a presença de negros é muitas vezes evitada pelas empresas que contratam modelos para os anúncios. No entanto, algum tipo de capital social pode abrir mais espaço para negociação. É o caso de modelos negros celebridades: “As pessoas não querem ser negras, as pessoas querem ser o Pelé” (BELELI, 2005, p. 98), afirmou um publicitário entrevistado. Por outro lado, a imagem do negro pode ser associada a um avanço por parte da empresa, que valoriza a ideia de diversidade.

\section{Metodologia}

A metodologia busca contribuir e dialogar com as perguntas suscitadas na revisão bibliográfica e observar quais as tendências predominantes de representação de mulheres negras e brancas na publicidade brasileira. Para tal, a revista Veja, semanal de maior 
circulação $^{2}$ do Brasil, foi analisada entre 2002 e 2017. Nesse período, uma revista foi selecionada por mês de modo aleatório - por sorteio -, e as publicidades encontradas foram codificadas em um formulário para registro dos modelos presentes nas peças. Desse modo, selecionamos 180 edições, com 6.913 peças publicitárias. Embora haja certa restrição na audiência da revista, esta ainda apresenta grande alcance, sendo espaço privilegiado de troca de valores culturais. A pesquisa foi realizada pelo Grupo de Estudos Multidisciplinares de Ações Afirmativas (GEMAA), sediado no Instituto de Estudos Sociais e Políticos da Universidade do Estado do Rio de Janeiro (IESP-UERJ).

Foram codificados 8.387 modelos segundo as perguntas do formulário, que incluíam: a) produto anunciado; b) tipo de anunciante (empresa privada, instituição pública, organização não-governamental etc.); c) marca; d) se existiam humanos; e) número de modelos; f) a raça - segundo as categorias do Instituto Brasileiro de Geografia e Estatística (IBGE) (preto, pardo, branco, amarelo ou indígena); g) gênero; h) se o modelo era um superbranco (pele clara, ruivo ou loiro de olhos azuis ou verdes); i) se o modelo era um supernegro (pele negra e cabelos crespos naturais); j) se o modelo era uma celebridade e qual; k) a atividade desempenhada pelo modelo no anúncio; 1) qual a vestimenta; m) faixa etária; n) se era representado de forma sexualizada; o) se era personagem em destaque; p) se havia interação entre os personagens e de que tipo; q) a expressão facial ; r) o espaço ocupado pela peça publicitária.

As hipóteses do trabalho seguem a bibliografia relatada na seção anterior, segundo a qual há sub-representação de negros e certo nível de estereotipia. No entanto, espera-se que haja distinções na representação de mulheres negras e mulheres brancas. Enquanto a visão de feminilidade hegemônica leva em consideração determinada performance, a hipótese é de que essas características são majoritariamente associadas a mulheres brancas, enquanto mulheres negras são mais fortemente associadas a trabalho, educação e outras características que muitas vezes divergem da feminilidade hegemônica.

Para determinar a classificação racial, a equipe optou por, em caso de dúvida, marcar os modelos como pardos, assinalando que houve dúvida. Essa escolha metodológica trabalha contra a hipótese de pesquisa, a fim de garantir resultados confiáveis. O banco de dados apresenta a separação entre pretos e pardos, porém, na

\footnotetext{
${ }^{2}$ Com mais de 556 mil leitores por semana (AUDIÊNCIA...2019), a revista também conta com uma ampla diversidade de anunciantes, dentre os quais estão empresas privadas, agências estatais, empresas de economia mista, organizações não governamentais, entre outros.
} 
análise, devido ao fato de apresentarem índices parecidos, foram somadas as categorias preto e pardo, colocadas aqui como negros.

\section{Características dos modelos dos anúncios por gênero e raça}

Os dados gerais da pesquisa contabilizam 8.387 modelos. Dentre eles, 6.810 são brancos (81\%), 1.202 são negros (15\%), 116 são amarelos (1\%), 248 não identificáveis (3\%) e indígenas não marcaram percentual igual ou maior do que 1\%, com apenas 12 indígenas na amostra. Para o presente artigo foram separados os resultados que dialogavam de modo mais direto com as perguntas trazidas, isto é, como a feminilidade é construída e como as mulheres negras dialogam com essa ideia na publicidade. Como mostra o Gráfico 1, as mulheres brancas chegam a quase paridade com os homens brancos ao longo dos anos. Já as mulheres negras e homens negros se encontram bem abaixo, com um crescimento reduzido com o passar do tempo.

Gráfico 1 - Percentual anual dos modelos de anúncios por gênero e raça.

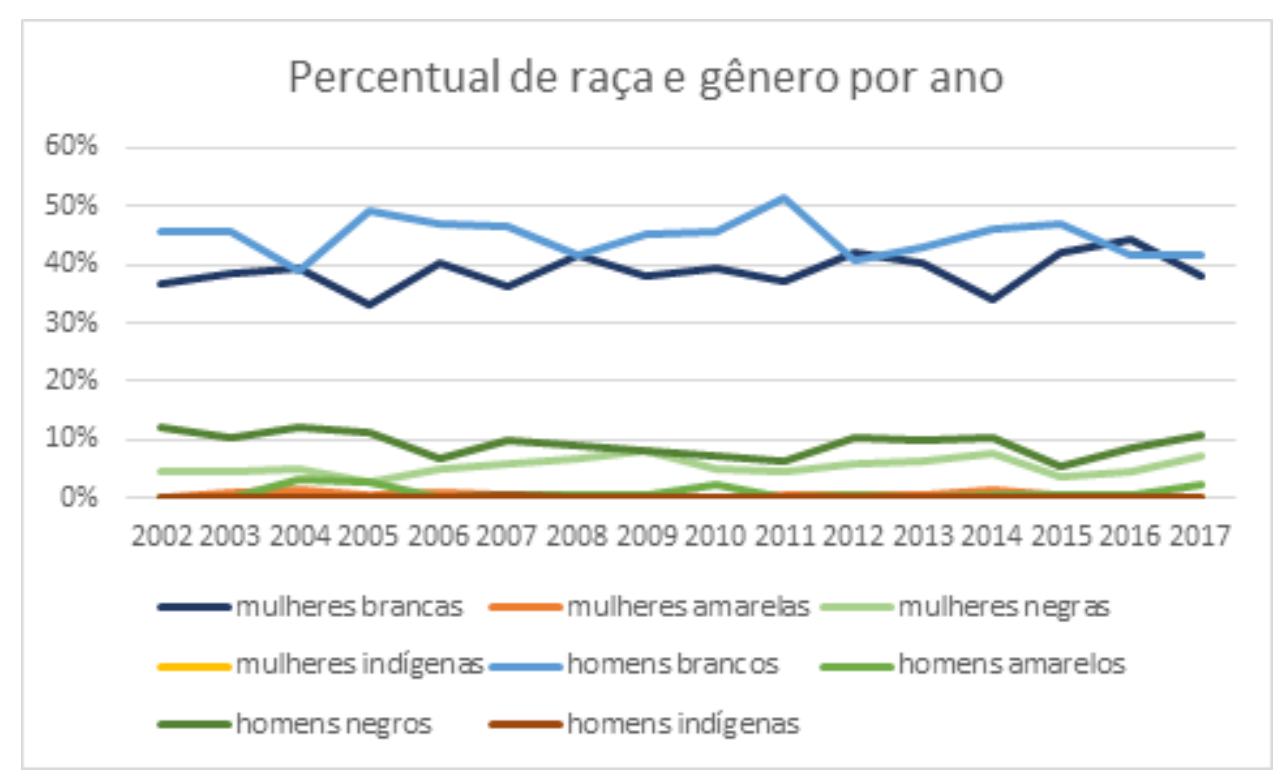

Fonte: GEMAA, 2019.

O número de pretos e pardos aumenta de forma modesta e um tanto oscilante ao longo dos anos e a razão entre as raças negra e branca é de 5,6. Em média, ao longo dos anos, o homem branco aparece $45 \%$; seguido de mulheres brancas, $39 \%$; homens negros, $9 \%$; mulheres negras 5\%; e homens e mulheres amarelos se encaixam no $1 \%$. A mulher negra é, portanto, a menos representada nos anúncios se comparada à sua parcela na população, de 28\% do total, segundo a PNAD contínua apresentada em 2018. 
A fim de dialogar com as pesquisas anteriores que identificaram a tendência a uma estética branca europeia (HASENBALG, 1982; MARTINS, 2009; SILVA; ROCHA; SANTOS, 2012), foi utilizada na codificação dos modelos a categoria superbranco. A categoria serve para descrever os seguintes traços: cabelos loiros de olhos azuis ou verdes ou cabelos ruivos naturais. A descrição serve também para saber se esses traços geram algum capital social a mais a depender da associação do modelo ao produto. Foi encontrado um recorte de gênero relevante nesse sentido: mais mulheres com os traços citados são representadas, sendo $15 \%$ do total de mulheres; quando os $100 \%$ fecham nos superbrancos, a mulher superbranca está em 73\%. A média de superbrancos é relevante, com $9 \%$ entre os brancos e $7 \%$ do total, superando o percentual de mulheres negras (5\%).

Foram analisados tipos de anunciantes que vão de empresas privadas a instituições públicas e Organizações não Governamentais (ONGs). Como exibido no Gráfico 2, a empresa privada foi a que mais investiu em publicidade na amostra, com 91\% dos anúncios observados. Negros, porém, estão duas vezes mais em peças de empresas estatais, e o triplo em propagandas de instituições públicas. Há uma distinção relevante entre as mulheres: enquanto as brancas estão em torno de $40 \%$ em anúncios de empresas privadas, as mulheres negras estão em 5\% (Gráfico 2). Elas estão proporcionalmente mais presentes em propagandas de empresas estatais, ONGs e instituições públicas, o que pode corroborar com resultados de pesquisas que associam a imagem da mulher negra a políticas assistencialistas (SILVA; ROCHA; SANTOS, 2012).

Gráfico 2 - Percentual de raça, gênero e tipos de anunciante na publicidade e propaganda.

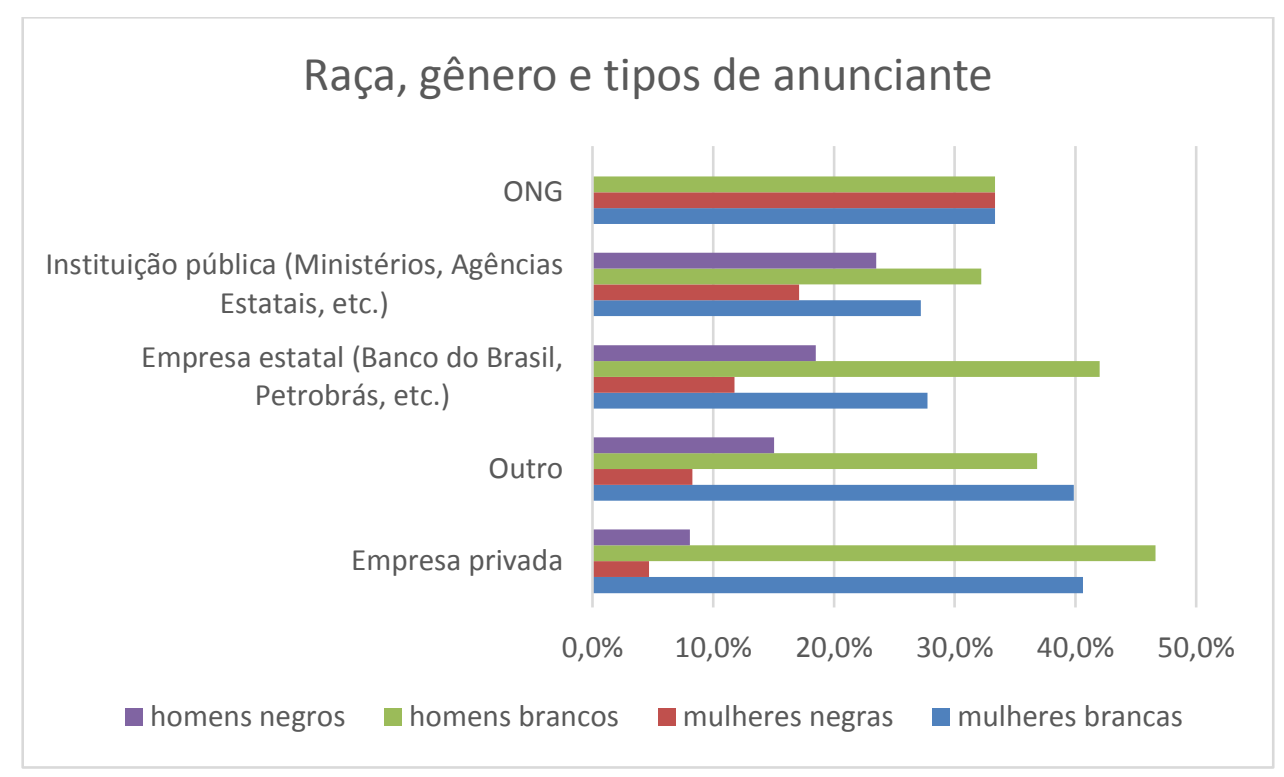


Fonte: GEMAA, 2019.

No Gráfico 3, pode-se observar as atividades desempenhadas pelos personagens nos anúncios. A "branquidade normativa” (SILVA; ROCHA; SANTOS, 2012, p. 149) se confirma fortemente na amostra, de modo que brancos são maioria na publicidade ( $84 \%)$ e também estão proporcionalmente em maior quantidade em todas as atividades simuladas nos anúncios. Todos os modelos apresentam maior proporção de imagens posando para a foto (apenas olhando para a câmera), seguido de lazer, e as demais atividades variam. No entanto, mulheres negras e brancas aparecem em maior proporção olhando para a câmera, enquanto mulheres negras e homens negros apresentam menor atividade de lazer.

Os homens apresentam maiores porcentagens de trabalho em geral - homens negros com a maior proporção nessa categoria -, e as mulheres negras aparecem, em ordem decrescente, simulando trabalho esportivo (3\%), braçal (3\%) e intelectual (3\%) se comparadas a mulheres brancas, que apresentam percentuais menores para as mesmas categorias, de $2 \%, 1 \%$ e $2 \%$, respectivamente. A maior incidência nos trabalhos esportivo e braçal mostra uma maior representação em profissões com menos status. A maior representação de mulheres pretas e pardas na atividade intelectual é uma informação contraintuitiva, ou seja, não esperada. De acordo com os resultados, mulheres negras estão mais associadas a trabalho e a atividades relacionadas à busca ou manutenção da independência financeira (Gráfico 3).

Gráfico 3 - Percentual anual de atividade dos personagens por gênero e raça.

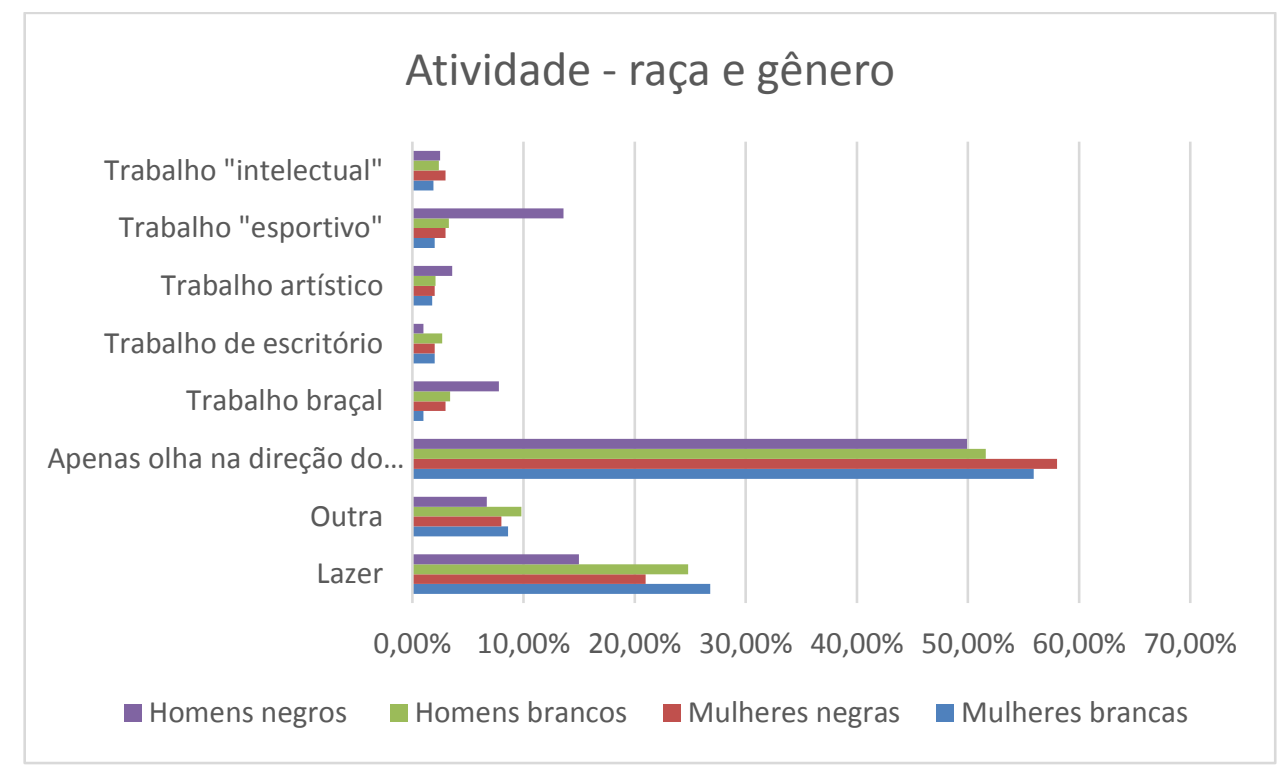


Fonte: GEMAA, 2019.

Na separação de produtos por gênero, pode-se notar que há certas marcas do que é representado como feminino e como masculino. Esses indicadores ganham tintas mais fortes quando se trata do universo feminino. Os produtos lidos socialmente como femininos geralmente são apresentados por modelos mulheres, o que acaba por dar instruções sobre formas em que esse grupo deve se comportar. Como é possível notar no Gráfico 4, os produtos com maior taxa de representação de mulheres são: joias (95\%), cosméticos $(73 \%)$ e roupas $(61 \%)$. Já os produtos com mais homens são: automóvel $(68 \%)$, bebida (65\%) e educação (63\%). Note-se que os produtos associados a mulheres têm menos homens representados e estão fortemente relacionados ao cuidado com a aparência; já os produtos masculinos são mais diversos, ao longo dos anos se tornam mais mistos em termos de gênero e são associados a habilidades intelectuais, lazer e autonomia.

Analisando sob a ótica de raça e gênero, mulheres negras são mais representadas em responsabilidade social $(17 \%)$ - quando uma empresa emite uma mensagem que promove a sua marca para além do produto em si, como, por exemplo, o apoio financeiro a uma $\mathrm{ONG}$ de educação -, o que destoa das mulheres brancas, com $4 \%$ nesse tipo de produto. Outra mercadoria na qual mulheres negras são mais representadas é serviço bancário ou financeiro (16\%), seguido de propaganda governamental, com 13\% de mulheres negras contra $2 \%$ de mulheres brancas. Por outro lado, os produtos mais tipicamente femininos são os que têm menos mulheres negras representadas, como: anúncios de roupas $(7 \%)$, joias $(6,5 \%)$ e cosméticos $(6 \%)$. Além disso, o percentual do grupo é baixo para medicamentos ou serviço de saúde (1\%) (Gráfico 4). 
Gráfico 4 - Percentual geral de tipo de produto entre mulheres brancas e negras. ${ }^{3}$

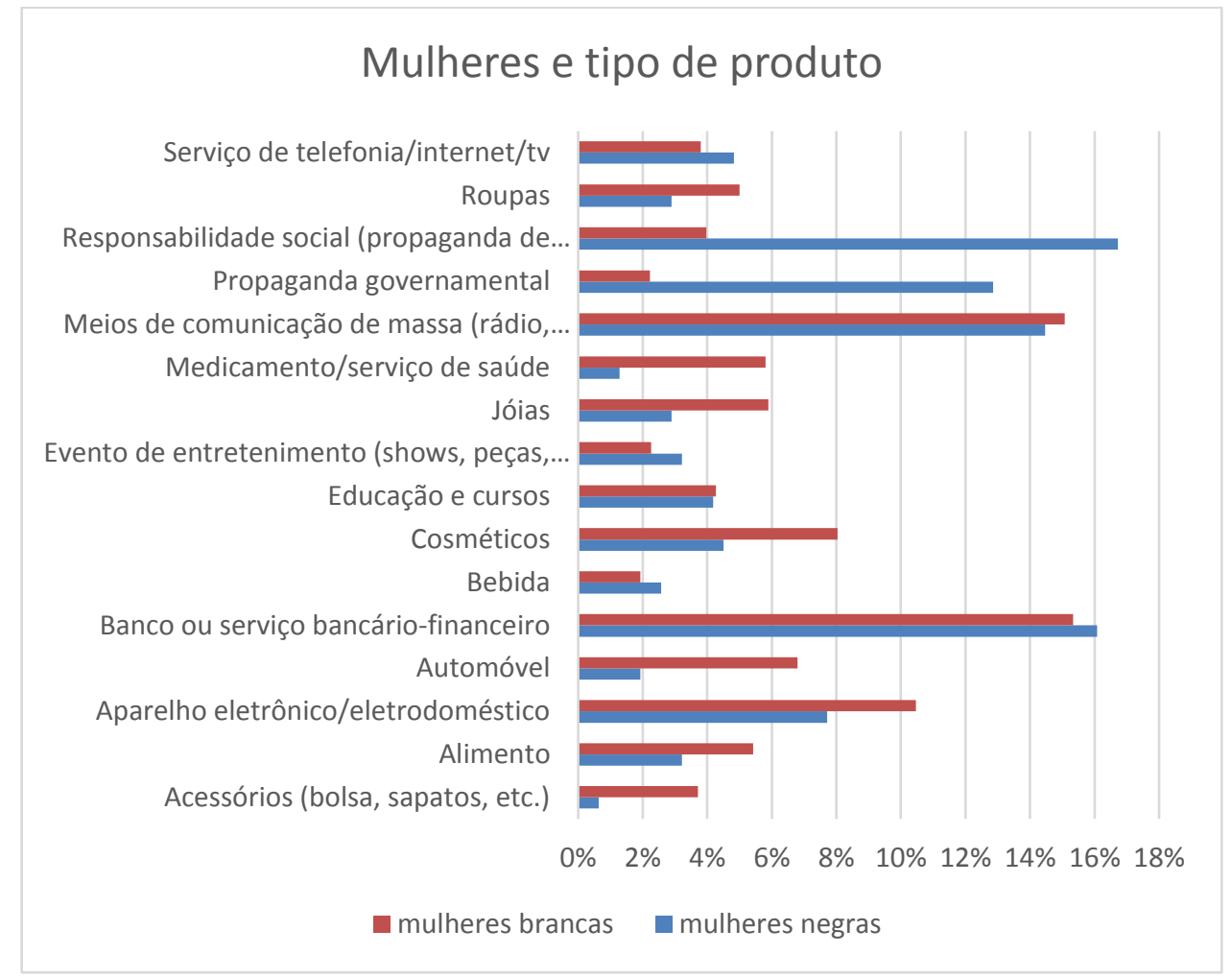

Fonte: GEMAA, 2019.

O uso de modelos superbrancos se deu para aferir a proporção desse grupo nos anúncios e em que tipo de contexto ele aparece. Ao observar o Gráfico 5, pode-se notar que as características de pele clara e cabelos e olhos claros está associada a produtos mais caros. Mulheres superbrancas estão principalmente em joias $(20,8 \%)$, produto de maior status social, meios de comunicação $(12 \%)$, serviço bancário $(10 \%)$ e roupas $(8 \%)$. A presença em meios de comunicação pode se dever ao fato de haver mais celebridades nesse tipo de publicidade, que obedece a um padrão europeu de aparência (ARAÚJO, 2006). Também há um percentual relevante de mulheres superbrancas em produtos associados a cuidados de beleza, como cosméticos (8\%) e acessórios (8\%).

\footnotetext{
${ }^{3}$ Os homens não estão presentes neste gráfico, embora façam parte da porcentagem para fechar $100 \%$.
} 
Gráfico 5 - Percentual geral de modelos superbrancos em anúncios por produto.

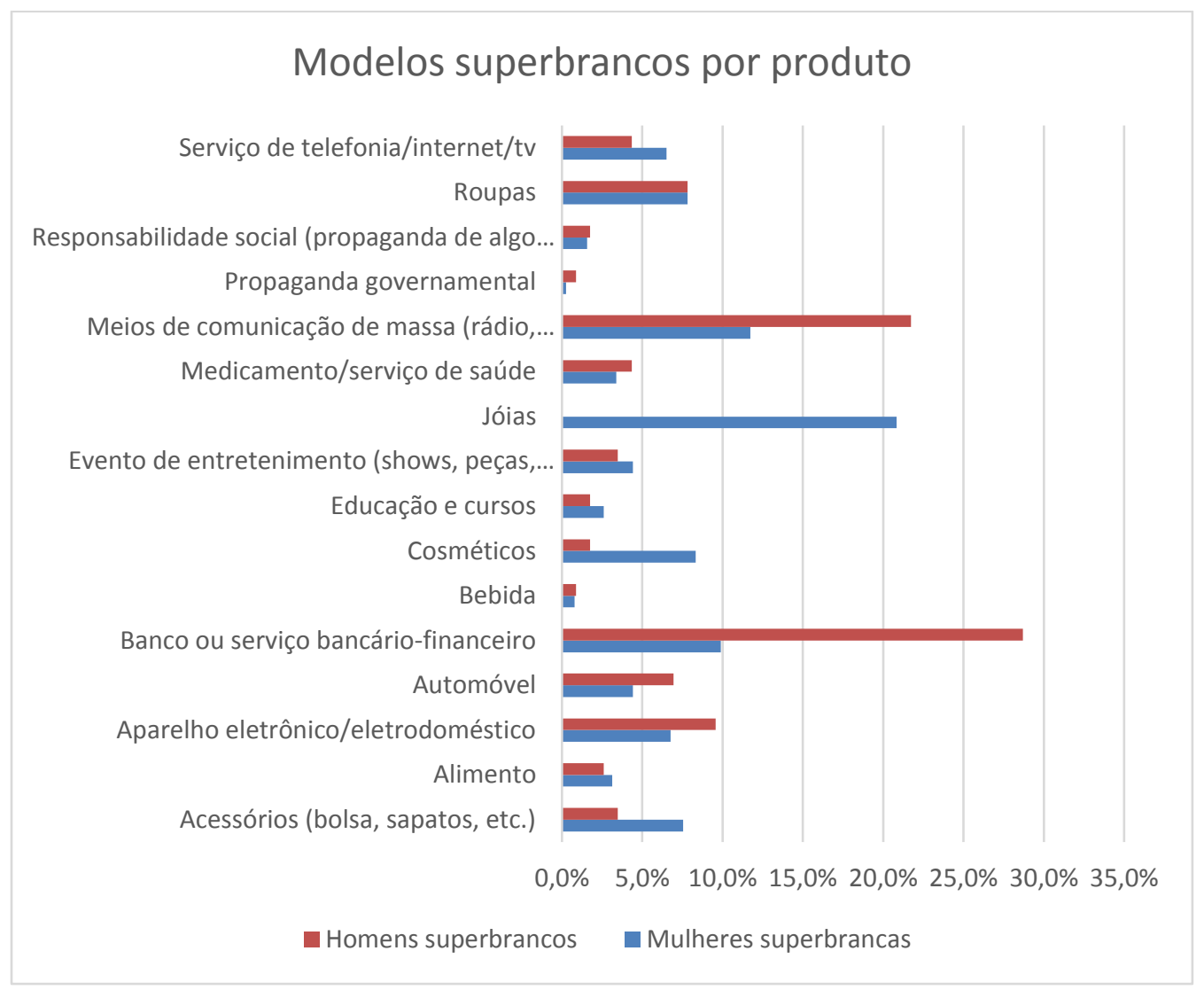

Fonte: GEMAA, 2019.

Outra variável relevante é a vestimenta dos modelos. Como evidenciado no Gráfico 6, em termos de gênero, homens são representados mais vezes com roupa de trabalho, mais especificamente uniforme de trabalho (27\% de homens negros e $6,2 \%$ de homens brancos), do que mulheres. As mulheres apresentam tendências de vestimenta parecidas. Contudo, mulheres negras se vestem mais com uniforme de trabalho (8\%), enquanto mulheres brancas estão em 5\% nessa descrição. Uniforme de trabalho, em geral, consiste em roupas de baixa remuneração. Com exceção de médicos e cientistas de laboratório, a maior parte de modelos caracterizados que precisa ir uniformizada ao trabalho é de baixa renda e/ou de trabalhos manuais. Elas também estão mais com roupa esportiva (6,2\% de mulheres negras e 3,4\% de mulheres brancas) e menos com roupa da moda ou conceitual (modelos brancas estão em 12\%, enquanto mulheres negras estão em $7,6 \%)$. 
Gráfico 6 - Percentual geral de roupas por gênero e raça.

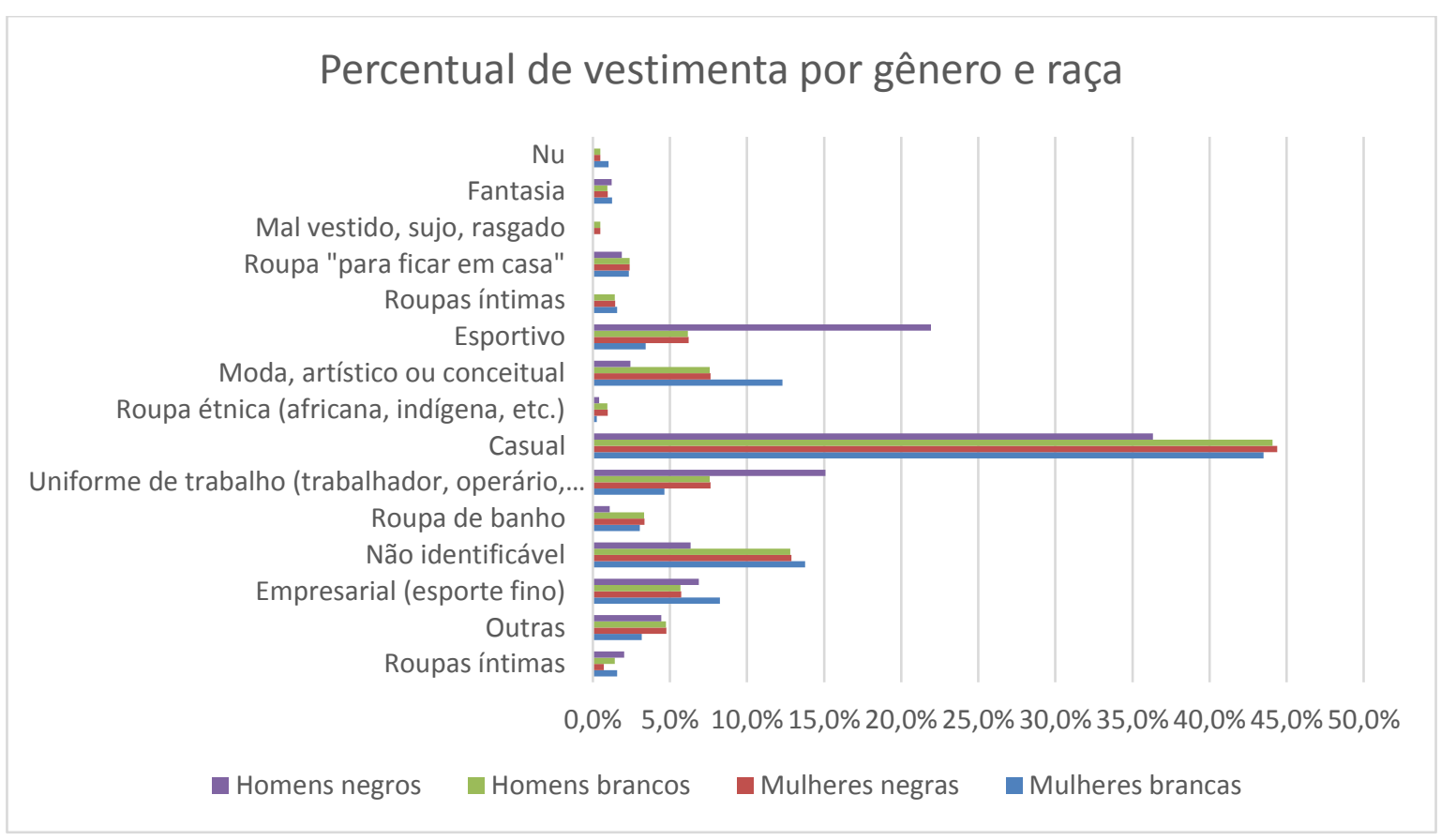

Fonte: GEMAA, 2019.

Para avaliar o nível em que os modelos são sexualizados na amostra, usou-se como critério a exposição de partes do corpo, como pernas, abdômen, coxas, entre outras. Os dados mostram que mulheres são mais sexualizadas do que os homens ( $6 \%$ contra $2 \%)$ e mulheres brancas foram mais sexualizadas do que mulheres negras (7\% e 3\%, respectivamente), embora a literatura ressalte a hiperssexualização da mulher negra (HASENBALG, 1982; MARTINS, 2009; SILVA; ROCHA; SANTOS, 2012). Na desigualdade aguda entre a representação de mulheres negras e brancas, embora a sexualização seja um tipo de objetificação e seja fruto do sexismo, a sedução e/ou a sexualização fazem parte da performance específica de beleza (BUTLER, 2003), a qual raramente é associada à mulher negra, na amostra.

As mulheres negras são as que apresentam menor porcentagem de celebridades como grupo, no entanto, os tipos de produto nos quais as modelos famosas são mais frequentes são joias (nesse produto, todas as mulheres negras que apareceram eram famosas, ou seja, 100\%), roupas (44\%), meios de comunicação (38\%) e cosméticos $(19 \%)$. 
Além da sub-representação evidente na amostra, há diversas estratégias de colocar mulheres negras em situação de subordinação, seja pela atividade desempenhada, pela mensagem que a publicidade transmite ou pelo número de modelos na peça. É comum que brancos apareçam mais vezes em destaque ou sozinhos, enquanto negros se veem rodeados de outros modelos brancos.

Desse modo, aspectos da feminilidade ideal, como a amabilidade, a aparência, subordinação e erotismo, se mostram representados, sobretudo, na mulher branca. A mulher negra parece apresentar uma feminilidade racializada, considerada incapaz de performar a feminilidade ideal, representada sobretudo pela mulher branca. Exceto a amabilidade e certa dose de subordinação contemplada a partir da maior proporção de sorrisos, há uma predominância de mensagens relacionadas à situação financeira da mulher negra, a suas possibilidades de ganho profissional, o que pode se observar pelas propagandas assistencialistas ou de responsabilidade social, pelas publicidades de serviço bancário, ou nas vestimentas relacionadas a trabalho ou esportes e sua maior representação no meio profissional.

\section{Considerações finais}

Pode-se concluir que a experiência hegemônica feminina é construída na publicidade a partir da figura da mulher branca, o que faz com que, além da pressão que as mulheres sofrem para atingir um ideal físico de difícil alcance, as mulheres negras precisam lidar com o fato de praticamente não existirem ali e de ter um ideal impossível, que é o de ser branca. O estreitamento das múltiplas versões de feminilidade - aliás, a feminilidade em si já é uma restrição, como se pode concluir na leitura de Butler (2003) - produz apagamento sobre mulheres não brancas.

A sobrerrepresentação de brancos em si já seria uma forma poderosa de apagamento, pois mostra que há uma norma de humanidade, a única capaz de gerar a identificação necessária para transmitir a mensagem da peça publicitária. Uma série de sentidos e hierarquias sociais é reafirmada na publicidade. Para além da divisão social do trabalho e dos espaços reservados a partir do gênero, a raça parece apontar para outras formas de dominação: homens trabalham mais do que mulheres, mas homens negros trabalham ainda mais, e em profissões de status socialmente entendidos como inferiores ou associados à ascensão, vide jogadores de futebol.

Ainda assim, embora sub-representados, homens negros apresentam alguma forma de ascensão aos olhos da sociedade, como atletas. A mulher negra atleta não recebe 
os mesmos holofotes ou prestígio, ainda que signifique algum status social. Embora a maior associação ao trabalho possa se traduzir em uma representação positiva da feminilidade, a imagem predominantemente ligada a propagandas assistencialistas desloca da figura hegemônica da mulher que de algum modo é dependente da aprovação masculina para a imagem de mulher dependente das ações do Estado ou de projetos sociais de empresas privadas.

Embora a publicidade não tenha o papel e nem o objetivo de representar a população, o uso de elementos sociais para transmitir sua mensagem é sintomático. $\mathrm{O}$ fato de haver uma população majoritariamente negra sub-representada, além de consumidores que não se veem nas peças, fala sobre formas sociais de identificação e de ideais estabelecidos socialmente. Isso pressupõe que, no cálculo para se pensar em um anúncio, mesmo que negros não se vejam representados, seguirão consumindo do mesmo modo, enquanto a narrativa sobre gênero - no caso, sobre a mulher branca - mudou de forma significativa ao longo dos anos, como se observa em pesquisas (EISEND, 2010) e na proporção de mulheres representadas revelada nos dados do presente artigo.

Desse modo, a combinação da sub-representação com a associação repetida de posições específicas menos reconhecidas socialmente desumaniza o grupo em alguma medida. Além da divisão de trabalho por gênero, há uma divisão por raça bem demarcada revelada nesta pesquisa. A negação ou negociação da imagem da mulher negra como investida de beleza se mostra como um dos pontos mais relevantes para o desvio da feminilidade. Na rejeição de sua aparência - rejeição que dialoga com contornos históricos - há uma forte imposição de uma estética branca no modo de ser mulher.

\section{Referências}

AUDIÊNCIA Geral. Veja, 2019. Disponível em:

http://publiabril.abril.com.br/marcas/veja. Acesso em: 6 jan. 2020.

ARAÚJO, Joel Zito. A força de um desejo - a persistência da branquitude como padrão estético audiovisual. Revista USP, São Paulo, n. 69, p. 72-79, mar./maio 2006.

BAKER, Christina N. Images of women's sexuality in advertisements: a content analysis of black- and white-oriented women's and men's magazines. Sex Roles, v. 52, p. 13-27, Jan. 2005.

BARTKY, Sandra Lee. Femininity and dominantion: studies in phenomenology of oppression. New York: Routledge, 1990.

BEAUVOIR, Simone de. O segundo sexo. São Paulo: Difusão Europeia do Livro, 
1970.

BELELI, Iara. Marcas da diferença na propaganda brasileira. 2005. Tese

(Doutorado em Ciências Sociais) - IFCH, UNICAMP, Campinas, SP, 2005.

BUTLER, Judith. Problemas de gênero: feminismo e subversão da identidade. Rio de Janeiro: Civilização Brasileira, 2003.

CARRERA, Fernanda. O discurso da ciberpublicidade: perspectivas conceituais para o estudo das estratégias discursivas da publicidade contemporânea. Questões

Transversais - Revista de Epistemologias da Comunicação, v. 4, n. 7, p. 37-45, jan./jun. 2016.

CARRERA, Fernanda Ariane Silva; OLIVEIRA, Luciana Xavier de. "Cabelo de Bombril"? Ethos publicitário, consumo e estereótipo em sites de redes sociais. Novos Olhares, v. 2, n. 1, p. 67-75, 30 jun. 2013. Disponível em:

http://www.revistas.usp.br/novosolhares/article/view/57042. Acesso em: 5 jul. 2019.

COLFAX, David; STERNBERG, Susan. The perpetuation of racial stereotypes: blacks in mass circulation. The Public Opinion Quarterly, v. 36, n. 1, p. 8-18, Spring 1972.

DÖRING, Nicola; PÖSCHL, Sandra. Images of men and women in mobile phone advertisements: a content analysis of advertisements for mobile communication systems in selected popular magazines. Sex Roles, v. 55, n. 3-4, p. 173-185, 2006.

EISEND, Martin. A meta-analysis of gender roles in advertising. Journal of the

Academy of Marketing Science, v. 38, n. 4, p. 418-440, 2010.

FRY, Peter. Estética e política: relações entre "raça", publicdade e produção da beleza no Brasil. Nu e vestido: dez antropólogos revelam a cultura do corpo carioca. 2. ed. Rio de Janeiro: Record, 2007. p. 303-326

GASTALDO, Édison Luís. "Negros jogam, brancos torcem": a ritualizaçõo das relações raciais na publicidade da Copa do Mundo. Ilha, Florianópolis, v. 4, n. 2, p. 99-110, dez. 2002.

GOFFMAN, Erving. Gender advertisements. New York: Harper Torchbooks, 1979.

GRADY, John. Advertising images as social indicators: depictions of blacks in LIFE magazine, 1936-2000. Visual Studies, v. 22, n. 3, p. 211-239, 2007.

HASENBALG, Carlos. O negro na publicidade. In: GONZALEZ, Lélia;

HASENBALG, Carlos. Lugar de negro. Rio de Janeiro: Marco Zero, 1982. p. 103-113.

HAZELL, Vanessa; CLARKE, Juanne. Race and gender in the media: a content analysis of advertisements in two mainstream black magazines. Journal of Black Studies, v. 39, n. 1, p. 5-21, 2008.

KOTLER, Philip; KELLER, Kevin. Administração de marketing. 14. ed. São Paulo: Pearson, 2012. 
LINDNER, Katharina. Images of women in general and fashion magazine advertisements from 1995 to 2002. Sex Roles, v. 51, n. 7-8, p. 409-410, Oct. 2004.

MARTINS, Carlos Augusto de Miranda e. Racismo anunciado: o negro e a publicidade no Brasil (1985-2005). 2009. Dissertação (Escola de Comunicações e Artes) Universidade de São Paulo, São Paulo, 2009.

NAVARRO, Luciane. Tudo muito claro: apagamento e pseudoinclusão da mulher negra na publicidade brasileira. Revista Mídia e Contexto, v. 1, n. 2, 2014.

SENGUPTA, Rhea. Reading representations of black, east asian, and white women in magazines for adolescent girls. Sex Roles, v. 54, n. 11-12, p. 799-808, 2006.

SHINODA, Luciana Messias. Padrões de representação do estereótipo do gênero feminino na propaganda brasileira. 2017. Dissertação (Mestrado em Administração) Fundação Getúlio Vargas, São Paulo, 2017.

SILVA, Paulo Vinícius Baptista da; ROCHA, Neli Gomes da; SANTOS, Wellington Oliveira dos. Negras(os) e brancas(os) em publicidades de jornais paranaenses.

Intercom: Revista Brasileira de Ciências da Comunicação, São Paulo, v. 35, n. 2, p. 149-168, jul./dez. 2012. Disponível em:

http://www.scielo.br/scielo.php?script=sci_arttext\&pid=S1809-

$58442012000200008 \& \operatorname{lng}=$ pt\&tlng=pt. Acesso em: 10 jun. 2019

STROZENBERG, Ilana. O apelo da cor: percepções dos consumidores sobre as imagens da diferença racial na propaganda brasileira. Comunicação Mídia e Consumo, v. 2, n. 4, p. 199-220, jul. 2005. Disponível em:

http://revistacmc.espm.br/index.php/revistacmc/article/view/43/44. Acesso em: 5 jul. 2019.

TATE, Shirley Anne. Black beauty: aesthetics, stylization, politics. Farnham: Ashgate, 2009.

WOLIN, Lori D.. Gender issues in advertising. Journal of Advertising Research, v. 43, n. 1, p. 111-130, 2003.

XAVIER, Giovana. Segredos de penteadeira: conversas transnacionais sobre raça, beleza e cidadania na imprensa negra pós-abolição do Brasil e dos EUA. Estudos Históricos, Rio de Janeiro, v. 26, n. 52, p. 429-450, jul./dez. 2013.

ZOTOS, Yorgos C.; TSICHLA, Eirini. Female stereotypes in print advertising: a retrospective analysis. Procedia - Social and Behavioral Sciences, v. 148, p. 446-454, 2014. Disponível em:

http://linkinghub.elsevier.com/retrieve/pii/S1877042814039688. Acesso em: 1 set. 2019. .

Submetido em: $14 / 10 / 2019$

Aprovado em: 30/10/2019 